\title{
A Wiki como ferramenta de aprendizagem coletiva: a percepção do aluno adulto
}

\author{
Simone H. de Campos, FACED/FACIN/PUCRS \\ simonehcampos@gmail.com \\ Márcia Cristina Moraes, FACIN/PUCRS \\ mmoraes@pucrs.br
}

\begin{abstract}
Resumo. O presente trabalho analisa o processo de colaboração de alunos adultos em wikis buscando embasamento teórico na teoria sócio-históricocultural de Vygotsky aplicada ao contexto das Novas Tecnologias de Comunicação e Informação. O principal objetivo foi compreender como alunos adultos reagem à forma de interação cooperativa que a wiki pressupõe. Para tanto, o trabalho propôs a dois grupos de alunos de Língua Inglesa a produção de um texto específico dos seus respectivos cursos em uma wiki. Após terminada a tarefa, ambos os grupos responderam a questionários explicitando suas impressões do processo.
\end{abstract}

Palavras-chave: Wiki, Aprendizagem Colaborativa, Interação.

\section{Wiki as a tool for collaborative learning: the perception of adult learner}

\begin{abstract}
This paper analyses the collaborative process of adult learners in wikis seeking its theoretical basis in Vygotsky' social-historical theory applied to the context of Information and Communication Technology. The main goal was to understand how adult learners react to the interactive cooperative format that a wiki presupposes. In order to do so, two groups of adult English Language students were asked to produce a specific text related to their course in a wiki. After finishing the task, both groups answered a questionnaire expressing their impressions on the process.
\end{abstract}

Keywords: Wiki, Collaborative Learning, Interaction.

\section{Introdução}

Uma nova era surgiu com o advento das novas tecnologias. É inegável que tal fato tenha imensas implicações em todas as áreas da vida humana. O campo da Educação também se insere nesse processo de mudança que vivemos desde 0 surgimento do computador e da Internet. Educar cidadãos para este novo contexto implica em incorporar as novas tecnologias a fim de preparar o indivíduo para que possa exercer sua cidadania plenamente.

Para Lévy (1999, p. 172), o desafio não se dá meramente no campo da mudança da formatação de uma educação na qual o aluno vai para a escola ou universidade para uma em o mesmo estuda à distância. Para o autor, o aspecto mais desafiador da cibercultura "é a transição de uma formação e uma educação estritamente institucionalizadas (a escola, a universidade) para uma situação de troca generalizada dos saberes, o ensino da sociedade por ela mesma”. 
O aluno adulto, que se vê no meio desse processo de mudanças e participa desta transição descrita por Lévy, precisa adaptar suas perspectivas e suas atitudes como aprendiz que é. Ao se preparar para o mercado de trabalho, o adulto precisa levar em conta as mudanças que Lévy (1999, p. 173) descreve ao afirmar que

"o trabalho não é mais uma execução repetitiva de uma tarefa atribuída, mas uma atividade complexa na qual a resolução inventiva de problemas, a coordenação no centro de equipes e a gestão de relações humanas têm lugares importantes."

Enquanto antigamente o foco estava nos limites de cada função ou profissão, com suas atribuições e conhecimentos muitas vezes relacionados a um diploma específico ou mesmo a uma disciplina, de acordo com Lévy (1999, p. 174), "no futuro, irá tratar-se muito mais de gerenciar processos: trajetos e cooperações”.

Dentro deste desafio de formar um aluno capaz de cooperar, o presente artigo busca sua fundamentação no referencial teórico sócio-histórico-cultura de Vygotsky para investigar as ações e reações de dois grupos de alunos adultos no processo de construção coletiva de textos utilizando a ferramenta wiki.

$\mathrm{O}$ artigo está organizado em quatro seções. Na seção 2 é apresentada a fundamentação teórica relacionada ao trabalho. Na seção 3 é apresentada a investigação desenvolvida e na seção 4 são discutidas as considerações finais.

\section{Wikis na construção coletiva e colaborativa do conhecimento}

De acordo com a AskOxford.com (2009), "uma wiki é um tipo de site desenvolvido colaborativamente por um grupo de usuários, e que pode ser facilmente acrescentado ou editado por qualquer pessoa." Ainda de acordo com a fonte supracitada,

“'Wiki' é uma palavra havaiana que significa 'rápido' (quando repetida significa 'muito rápido') e foi usada pela primeira vez com este sentido em 1995 pelo programador de computadores americano Ward Cunningham, que chamou seu site de WikiWikiWeb. A mais conhecida wiki é provavelmente a Wikipedia (uma enciclopédia online em que pessoas podem contribuir com artigos)."

Uma wiki pressupõe interação, colaboração e construção coletiva de um determinado saber. $\mathrm{O}$ foco passa de uma educação centrada em um indivíduo isolado com suas potencialidades limitadas para uma educação focada na coletividade, que permite ao indivíduo o desenvolvimento de uma inteligência cada vez mais global e completa.

Também para Vygotsky a chave da construção do conhecimento está na interação. Com base na sua análise do desenvolvimento infantil, o autor chegou à conclusão que há basicamente dois níveis distintos no processo de aprendizagem e o intervalo entre esses dois níveis o autor denominou Zona de Desenvolvimento Proximal. De acordo com o Vygotsky (1998, p.112), Zona de Desenvolvimento Proximal

"é a distância entre o nível de desenvolvimento real, que se costuma determinar através da solução independente de problemas, e o nível de desenvolvimento potencial, determinado através da solução de problemas sob a orientação de um adulto ou em colaboração com companheiros mais capazes."

Em colaboração com o outro mais capaz, seja este um professor ou colega mais experiente, o indivíduo adquire habilidades e constrói conhecimentos que poderá utilizar para resolver problemas iguais ou parecidos de forma independente num futuro momento. 
Portanto para Vygotsky, a aprendizagem e o desenvolvimento do indivíduo são processos que se dão fundamentalmente nas relações sociais entre indivíduos em diferentes estágios cognitivos. Se é necessário que haja interação com o outro mais experiente para alcançar a solução um determinado problema, as interações sociais se fazem fundamentais na aprendizagem. Os saberes de um indivíduo se constroem na medida em que este busca interagir com seus pares, compartilhando suas experiências e adquirindo saberes que o outro já possui.

Na perspectiva sócio-interacionista de Vygotsky, é através do contato com o mundo e com o outro que se dá a internalização do saber. A wiki, ao promover o espaço para a colaboração na construção de um texto, se torna o terreno onde estas relações podem acontecer.

Brandão e Corazza (2008, p. 5) afirmam, com base em suas leituras de Vygotsky, que

"À medida que se propicia um ambiente coletivo de socioconstrução, o conhecimento é elaborado em dois momentos: primeiro em nível interpessoal, com a ajuda do outro, e em um segundo momento em nível intrapessoal, quando ocorre a apropriação do conhecimento pelo indivíduo.”

Para os autores, "como a aprendizagem não resulta da atividade em si, mas das interações sociais que é capaz de desencadear, o objetivo da produção coletiva de um ambiente virtual colaborativo, é promover interações sociais que permitam a aprendizagem de determinado conteúdo”. A wiki é uma ferramenta com grande potencial para que aprendizagens desta natureza aconteçam.

\section{Um experimento de utilização de wiki por alunos adultos}

A fim de observar como o aluno adulto se articula ao se deparar com esta nova possibilidade de construção coletiva e colaborativa do conhecimento, foi realizada uma investigação com grupos de alunos de Língua Inglesa de uma escola particular de línguas. A referida escola foca constantemente na utilização de ferramentas tecnológicas na tentativa de expandir a utilização da Língua Inglesa fora do contexto de sala de aula a fim de maximizar o aprendizado do aluno. A cada semestre professores e grupos de alunos pilotam projetos idealizados pelo departamento acadêmico da instituição, utilizando novas tecnologias visando experimentar possibilidades de trabalho com as mesmas.

No segundo semestre do ano de 2009, a instituição lançou o projeto Digital Immersion (Imersão Digital) a fim de investigar mais de perto como cada uma das ferramentas tecnológicas disponíveis poderia ser utilizada com o objetivo de expandir as oportunidades de aprendizagem da Língua Inglesa. Todos os professores foram convidados a escolher uma ferramenta de sua preferência e desenvolver com um de seus grupos de alunos um projeto de sua própria autoria. Os projetos tiveram a duração de no máximo seis semanas. Ao final do projeto, cada professor escreveu um relatório descrevendo como foi o desenrolar do mesmo, bem como destacando aspectos positivos e negativos da ferramenta utilizada. Outro ponto importante que foi considerado no relatório foi a atitude e participação dos alunos no projeto.

Neste contexto de experimentação, foi realizada a investigação do potencial da wiki como ferramenta de construção coletiva de textos por duas professoras (a autora e uma colega). Cada uma das professoras trabalhou com uma turma individualmente. A primeira turma era composta por sete (7) alunos com idade entre 20 e 30 anos que estavam se preparando para realizar o exame International English Language Testing 
System (IELTS). A segunda turma era composta por seis (6) alunos com idade entre 20 e 30 anos que estavam se preparando para o exame First Certificate of English (FCE). A turma, orientada pela a autora, colaborou na construção coletiva de um Essay (texto de opinião solicitado no exame IELTS). A turma orientada pela professora colega colaborou na construção de um Film Review (que é um texto de crítica de filme que é solicitado no exame FCE).

Para executar as tarefas, foi escolhido 0 site Wikispaces (http://www.wikispaces.com). De acordo com Mantovani e Viana (2008, p.4),

"O Wikispaces é um site para hospedagem gratuita de wikis criado em 2005. Neste ambiente os usuários podem criar suas próprias páginas wikis facilmente, alterando o layout, escolhendo templates, criando links de navegação. $\mathrm{O}$ ambiente pode ser gerenciado pelo seu criador/administrador que pode autorizar os seus convidados a fazer alterações, editando novas páginas e novos links. Estas páginas podem ficar abertas para serem editadas por qualquer pessoa ou protegidas para que apenas os convidados possam editar. Não é necessário utilizar palavras wikis, ou seja, linguagem de marcação, pois apresenta barra de ferramentas própria para formatação de textos, inserção de imagens, áudios, vídeos e links de navegação. No wikispaces é possível a integração de várias ferramentas da Web 2.0 tais como vídeos, áudios, mapas,

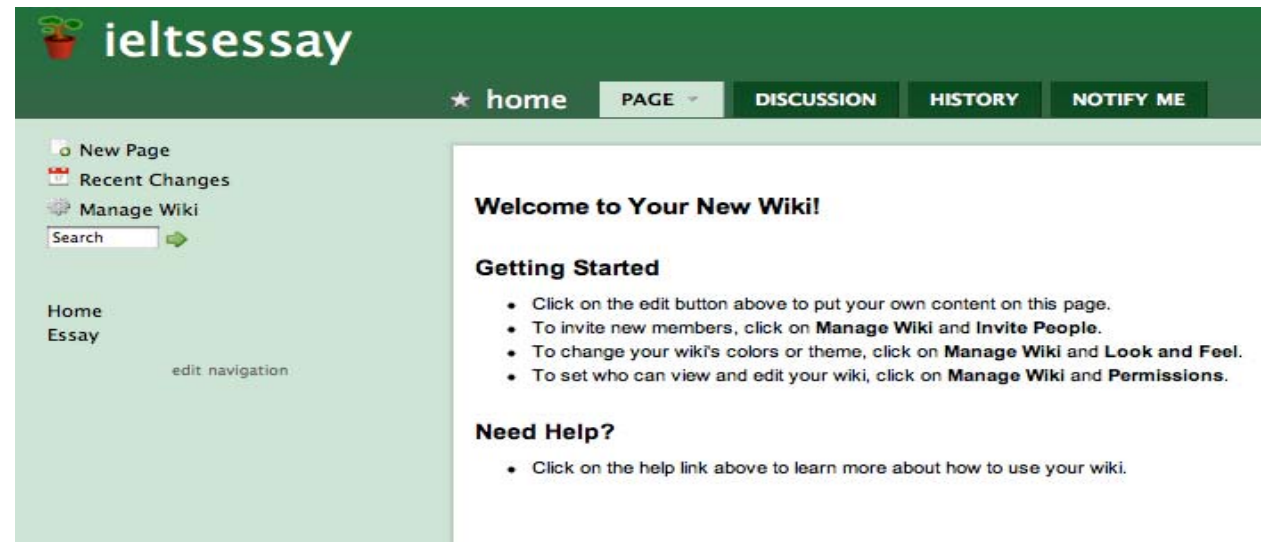

slideshow, RSS, etc.”

Além disso, o site possui um fórum de discussão que permite que haja a interação sobre o texto que está sendo produzido colaborativamente. Este foi um dos motivos pelos quais a ferramenta foi escolhida pelas professoras.

As professoras elaboraram a proposta de escrita no site da Wikispaces e enviaram a cada um dos alunos o convite que lhes permitisse o acesso à página. Após, cada aluno deveria acessar a página, criar uma conta e iniciar sua colaboração. A página inicial da Wikispaces pode ser visualizada na figura 1.

Figura 1. Página inicial da Wikispaces

\subsection{Metodologia}

As professoras utilizaram metodologias distintas para trabalhar com a wiki. Para trabalhar com a wiki Essay a professora optou por realizar todas as interferências e interações a respeito do texto através do fórum disponível na página do Wikispaces. Os alunos discutiram e tiraram suas dúvidas a respeito do texto no fórum e o texto não foi 
aberto ou discutido em sala de aula. As correções necessárias ao texto foram sugeridas muito esporadicamente pela professora no fórum. A figura 2 apresenta a página

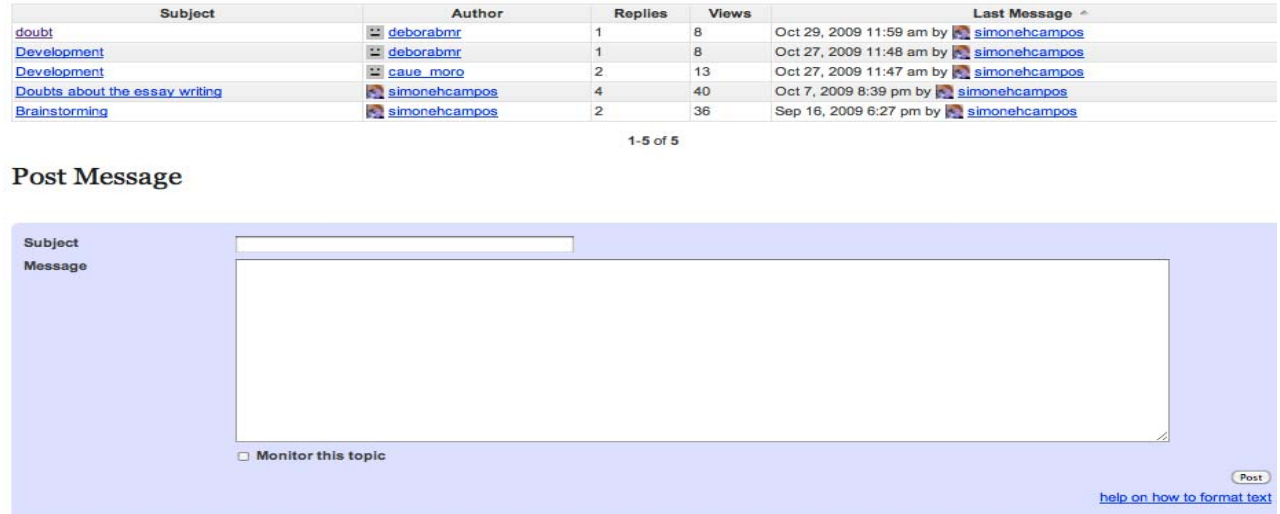

contendo o fórum do grupo Essay na Wikispaces.

Figura 2. Página do fórum de discussão do grupo Essay

A professora que trabalhou com o texto Film Review preferiu sugerir mudanças, adaptações e correções em sala de aula, não utilizando o fórum disponível na ferramenta. O texto foi aberto durante as aulas e foi discutido pelos alunos com a professora. A professora procurava direcionar os alunos para que usassem itens de vocabulário bem como estruturas gramaticais que haviam sido aprendidas em aula.

A wiki ficou em construção por aproximadamente seis semanas, durante as quais os alunos acessaram e construíram o texto colaborativamente. Após esse período, um questionário, ilustrado na figura 3 , foi aplicado a fim de identificar as impressões dos alunos relacionadas à sua motivação para a colaboração em trabalhos desta natureza.

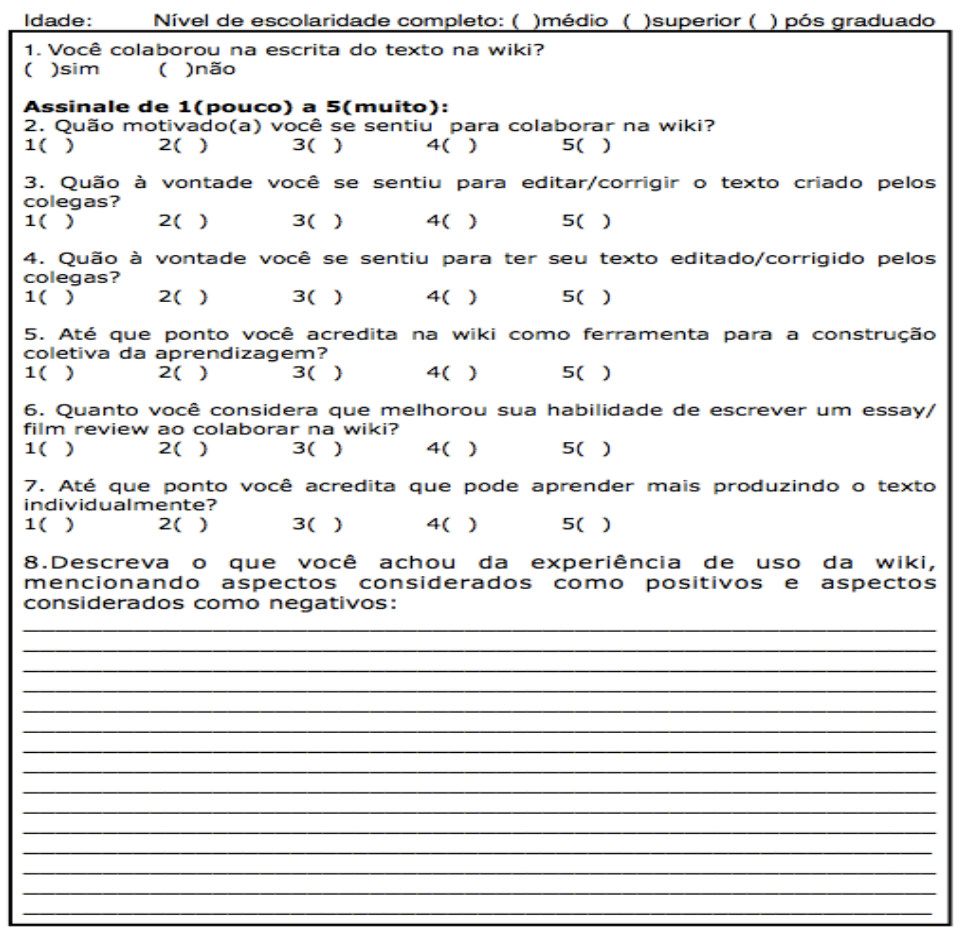

Figura 3. Questionário aplicado nos grupos 


\subsection{Análise das respostas dos alunos}

Para a análise dos resultados obtidos com o questionário, é preciso salientar que, em geral, as turmas de alunos em cursos de Inglês são bastante pequenas, especialmente no curso preparatório para o exame IELTS. À medida que o aluno se inscreve e realiza a prova, ele cancela sua matrícula e passa a não mais ser parte da turma de alunos que desenvolveu o texto Essay.

Os próximos parágrafos descrevem as observações realizadas sobre 0 questionário aplicado ao grupo Essay.

Na questão 1, o aluno identifica se participou na construção do texto na wiki ou não. No grupo que construiu a wiki Essay haviam inicialmente onze alunos, dos quais quatro saíram do curso ao longo do projeto. Apenas um dos desistentes participou efetivamente da construção da wiki, mas não se encontrava mais matriculado na ocasião da aplicação do questionário. Dos 7 alunos restantes, apenas dois alunos se envolveram no projeto colaborando com a escrita da wiki.

Na questão 2, que perguntava sobre o grau de motivação dos alunos, observouse que o nível desta foi média-alta. Na questão 3 , que questionava quão à vontade 0 aluno se sentiu para editar o texto do colega, as respostas denotam um grau de constrangimento considerável. Já na questão 4, que perguntava sobre quão à vontade 0 aluno se sentia para ter seu texto editado por um colega, não houve constrangimento algum. Quando questionados a respeito da wiki como ferramenta de construção coletiva da aprendizagem na questão 5 , os alunos percebem a wiki como tendo um potencial médio para tal.

Ao serem questionados a respeito das suas percepções sobre a própria aprendizagem com a utilização da wiki, os alunos manifestam que não perceberam grande desenvolvimento, podendo ser este ser considerado médio-baixo. Na questão sobre a possibilidade de aprender mais produzindo o texto em questão individualmente, a percepção dos dois alunos foi bem distinta. Um deles respondeu que seria baixa tal possibilidade, enquanto outro acredita que esta é média.

Na questão 8, onde o aluno pode se manifestar livremente sobre sua experiência de uso da wiki, mencionando aspectos que o mesmo considerou positivos e negativos, ambos alunos respondentes consideraram baixa a interação entre os colegas. Um dos alunos apontou como aspecto negativo “o fato de a ferramenta não ter sido massivamente utilizada", acrescentando ainda que isto "prejudicou um pouco o processo pela falta de diferentes contribuições" e que "falta um pouco de interação mais explícita com os colegas”. Também nessa mesma linha de raciocínio, outro aluno afirma que o resultado do trabalho poderia ter sido melhor caso o "texto fosse produzido online com a maior quantidade de alunos presentes". Todos os alunos manifestaram dificuldade de editar o trabalho dos colegas. Isso se explicita no "embaraço de corrigir textos produzidos por outros" manifestado por um aluno. Para outro aluno, "a liberdade de alterar o trabalho dos colegas é uma novidade” e que não há ainda este hábito na sala de aula.

Entre os alunos que não participaram da produção do Essay na wiki, ressalta-se nas respostas à questão 8, a falta de tempo para tal, apesar das manifestações de apoio por considerarem a tarefa produtiva para aprendizagem. Na questão 7 , os alunos que não colaboraram na wiki mostraram uma crença predominante na possibilidade de aprender mais produzindo o texto individualmente, o que pode ser um fator que os motivou a não tomar parte na tarefa.

Os próximos parágrafos descrevem as observações realizadas sobre o questionário aplicado ao grupo Film Review. 
Todos os seis alunos matriculados no curso participaram da construção do texto na wiki no grupo Film Review. Entretanto, dos seis alunos em questão, apenas quatro responderam ao questionário.

Na questão 2, que perguntava sobre o grau de motivação dos alunos, foi possível notar que esta foi média-alta, tal como no grupo que trabalhou com o Essay. Na questão 3, que questionava quão à vontade o aluno se sentiu para editar o texto do colega, as respostas denotam uma variação considerável no grau de constrangimento. Há um aluno para o quesito pouco e dois alunos para o quesito muito, encontrando-se um aluno entre esses dois pontos.

Na questão 4, que perguntava sobre quão à vontade o aluno se sentia para ter seu texto editado por um colega, três alunos se posicionaram como muito à vontade e apenas um manifestou um certo constrangimento. Quando questionados a respeito da wiki como ferramenta de construção coletiva da aprendizagem, os alunos mostraram perceber a wiki como tendo um potencial consideravelmente alto para tal, sendo bem mais confiantes do que os alunos que trabalharam com o Essay.

Ao serem questionados a respeito das suas percepções sobre a própria aprendizagem com a utilização da wiki, os alunos demonstram que perceberam algum desenvolvimento, podendo ser este considerado médio-alto. $\mathrm{Na}$ questão sobre a possibilidade de aprender mais produzindo o texto em questão individualmente, a percepção dos alunos foi bastante similar, ficando esta num patamar médio. Na questão 8 onde, como já foi mencionado, o aluno pode manifestar-se livremente sobre sua experiência de uso da wiki, mencionando aspectos que o mesmo considerou positivos e negativos, três entre quatro alunos relataram ter observado melhora na sua utilização do vocabulário de Língua Inglesa.

Isso fica evidente na seguinte frase escrita por um dos alunos: “A atividade contribuiu para a melhora em relação ao vocabulário, pois estávamos sempre tentando achar novas palavras e sinônimos para as utilizadas anteriormente.” Outro aluno afirma que "o trabalho acrescentou bastante no vocabulário, não só aquele trabalhado especificamente para esse tipo de texto, mas aquele utilizado pelos colegas”. Na opinião de outro aluno, "através da wiki, podemos expor com liberdade nossas opiniões e também compartilhar conhecimento, aumentando vocabulário e desenvolvendo o modo como escrevemos”.

Ainda na questão 8, todos os quatro alunos respondentes consideraram positivo o fato de compartilhar conhecimentos e aprender com os outros. Um dos alunos explicitou que achou "a atividade muito interessante", porque pode "trocar idéias com os colegas". Outro aluno também afirma ter achado a "atividade muito interessante" sugerindo a utilização futura em outros momentos por acreditar "ser uma forma de desenvolver a língua com criatividade e interação com os colegas”. Nesse mesmo sentido, um dos alunos manifestou que, além da diversão proporcionada pela wiki, "valeu a pena escrever em grupo pois todos tiveram boas idéias e cada um enriqueceu o texto um pouco".

\section{Conclusões}

Após a análise dos dados coletados através do questionário e previamente descritos na seção 3.2, foi possível perceber que, em linhas gerais, um maior sucesso em termos de percepção e motivação foi explicitado pelos resultados dos alunos que trabalharam com o Film Review.

Tal fato fica mais evidente nas respostas à questão 6, que pergunta sobre a aprendizagem percebida com a wiki. Para os alunos que produziram o Essay não houve 
percepção de grande desenvolvimento, sendo que as respostas marcadas foram nos níveis 2 e 3, considerando-se 1 pouco e 5 muito. Já para os alunos que desenvolveram o Film Review, houve claramente a percepção de que o trabalho os fez progredir no aprendizado. Houve uma resposta para nível 3 e três respostas para nível 4, numa progressão de 1 para pouco e 5 para muito.

As respostas dos alunos à questão 8, de natureza aberta e discursiva, são de fundamental importância para a compreensão de como o processo foi percebido distintamente pelos dois grupos de alunos. Os alunos que trabalharam com o Essay sentiram que a baixa interação foi um fator desmotivador no processo. Novamente referenciando as palavras dos alunos, foi apontado "o fato de a ferramenta não ter sido massivamente utilizada" e que isto "prejudicou um pouco o processo pela falta de diferentes contribuições" e, ainda, que "falta um pouco de interação mais explícita com os colegas".

Outro aspecto negativo que foi mencionado pelos alunos que construíram o Essay foi a questão do "embaraço de corrigir textos produzidos por outros" e que "a liberdade de alterar o trabalho dos colegas é uma novidade”. Fica evidente que a idéia da wiki como um espaço de construção coletiva ficou inviável pelos fatores acima mencionados. Os alunos pouco ou nunca se utilizaram da sua liberdade para organizar e melhorar o texto do grupo se isso implicasse em editar o que o colega escreveu. Corrobora com esta idéia o fato de que os alunos que não participaram da escrita do texto Essay na wiki manifestaram na questão 7 uma crença predominante na possibilidade de aprender mais produzindo o texto individualmente. Os três respondentes que não participaram da tarefa escolheram os níveis 3 , 4 e 5 quando perguntados sobre o quanto acreditam na possibilidade de aprender mais trabalhando individualmente, entre as opções 1 , para pouco, até 5 , para muito.

A análise acima leva a alguns questionamentos para futuras investigações, dentre os quais, o de que talvez os alunos adultos, por terem passado por um sistema educacional ainda bastante focado em atividades individuais e por terem obtido sucesso com base apenas no que o indivíduo é capaz de produzir por si só, não estão abertos para essa forma de construção do conhecimento.

Outro aspecto que deve ser relembrado neste momento de conclusões, e que parece ser de fundamental importância na compreensão das motivações dos alunos, é o da metodologia utilizada pelo professor. No texto Essay houve pouca interferência e o professor se limitou a apontar alguns problemas de ordem gramatical e vocabular no texto. O trabalho não foi aberto em sala de aula a fim de permitir que o aluno pudesse ter total autonomia na suas intervenções na wiki. Isso leva a outra possível conclusão que precisa ser aprofundada numa futura investigação: os alunos adultos, por terem sido moldados num formato de escola em que o professor é o principal agente na construção da aprendizagem, não sabem como lidar com a autonomia que a wiki oferece.

Nesse sentido, a metodologia utilizada pelo professor que trabalhou com os alunos no Film Review foi mais tradicional. A wiki foi aberta em sala de aula, para que o professor pudesse orientar e sugerir mudanças no texto. Isto certamente influenciou o nível motivação dos alunos, que se viram em um ambiente mais próximo do tradicional e tiveram, portanto, mais segurança para construir o texto.

As respostas dos alunos que construíram a wiki Film Review parecem apontar também nesta direção. Na questão sobre a possibilidade de aprender mais produzindo o texto em questão individualmente, a percepção dos alunos foi bastante positiva, ficando esta num patamar médio com três respostas para nível 3 e uma resposta para nível 4, num leque de 1 para pouco e 5 para muito. 
Na questão aberta, de número 8, três entre quatro alunos que construíram o Film Review relataram ter observado melhora na sua utilização do vocabulário de Língua Inglesa, relatando que "a atividade contribuiu para a melhora em relação ao vocabulário, pois estávamos sempre tentando achar novas palavras e sinônimos para as utilizadas anteriormente.” e que "o trabalho acrescentou bastante no vocabulário, não só aquele trabalhado especificamente para esse tipo de texto, mas aquele utilizado pelos colegas".

Embora o presente trabalho não se proponha a fazer afirmações categóricas a respeito dos resultados encontrados, algumas direções podem ser apontadas para se compreender o processo descrito. Parece ficar claro que os alunos adultos se sentem mais motivados a trabalhar em projetos que se assemelham com o formato de escola onde obtiveram sua formação inicial. A possibilidade de trabalhar co-operativamente aparentemente diminui a motivação dos alunos para a participação nas atividades propostas. Existe ainda bastante pudor ao se trabalhar com a possibilidade de intervir na produção do outro.

Alunos adultos, aparentemente mais dependentes da iniciativa do professor e receosos de intervir na tarefa da maneira colaborativa que a wiki pressupõe, precisam de um apoio no sentido de realizar uma transição de um formato tradicional, centrado no professor, para o formato que a perspectiva sócio-interacionista de Vygotsky e das Novas Tecnologias de Informação e Comunicação propõem. Num primeiro momento, talvez se faça necessário que o professor interfira mais do que o que seria esperado numa wiki, a fim de dar ao aluno a segurança necessária para tomar parte na tarefa. Dessa forma, o aluno poderá construir a segurança e as habilidades necessárias para interagir e colaborar de forma mais independente numa próxima oportunidade.

\section{Referências}

ASKOXFORD. Disponível em: <http://www.askoxford.com/worldofwords/ bubblingunder/archive/bubbling_03/?view=uk >. Acessado em 26 Out. 2009.

BRANDÃO, L. e CORAZZA, M. J. Produção de wiki: uma ferramenta pedagógica para o desenvolvimento do pensamento conceitual dos estudantes do Ensino Médio. (2008) Disponível em: <www.diaadiaeducacao.pr.gov.br/ portals/pde/arquivos/281-4.pdf>. Acessado em 24 Nov 2009.

LÉVY, P. Cibercultura. 1ª Ed. São Paulo: Ed 34, 1999.

MANTOVANI, Ana Margô; VIANA, Cristiane de Carvallho. Construção Colaborativa de Ambiente de Aprendizagem com o uso de Wiki. (2008) Disponível em: <http://www.seminfo.com.br/anais/2008/pdfs/seminfo/3-50748.pdf >. Acessado em: 26 Out. 2009.

VYGOTSKY, L. S. A Formação Social da Mente. São Paulo, Martins Fontes, 1998. 